\title{
Characteristics of mood-congruent and mood-incongruent psychotic features in bipolar disorder
}

\author{
Pradhyuman Chaudhary ${ }^{1}$, Nimesh Parikh², Prateek Sharma³ \\ ${ }^{1}$ Department of Psychiatry, GMERS Medical College and Hospital, Sola, Ahmedabad, Gujarat, India \\ ²Department of Psychiatry, Smt. NHL Municipal Medical College and SVPIMSR Hospital, (Affiliated under Gujarat University), \\ Ahmedabad, Gujarat, India \\ ${ }^{3}$ Karuna Neuro-Psychiatry Hospital, Sangrur Kty, Sangrur, Punjab, India \\ Neuropsychiatria i Neuropsychologia 2021; 16, 1-2: 66-75
}

Address for correspondence:

Pradhyuman Chaudhary, MD

Department of Psychiatry, GMERS Medical College and Hospital,

Sola, Ahmedabad, Gujarat

India

phone: 919825411772

e-mail: drpradhyuman@gmail.com

\begin{abstract}
Introduction: Psychotic features in patients with bipolar disorder (BD) have been poorly researched in the context of their relationship with the longitudinal course and demographic and clinical characteristics of the illness. Material and methods: In a cross-sectional study of BD patients, comprehensive demographic and clinical characteristics were assessed using the Structured Clinical Instrument for DSM-IV-TR (SCID). Manic symptoms were assessed using Young's Mania Rating Scale (YMRS), depressive symptoms by the Montgomery-Åsberg Depression Rating Scale (MADRS) and psychotic symptoms with the Scale for Assessment of Positive Symptoms (SAPS). The relationships between these characteristics and psychotic symptoms were analysed. The independent samples $t$-test was used to assess continuous variables, while the $\chi^{2}$ test was used to assess categorical data.

Results: Psychotic features were associated with BD in $48.94 \%$ of patients $(n=92$ out of a total of 188 patients having BD). Of these, $45.74 \%(n=86)$ had mood-congruent psychotic features and $3.19 \%(n=6)$ had mood-incongruent psychotic features. All six patients who had mood-incongruent psychotic features had manic symptoms.

Conclusions: Our findings suggest that mood-congruent psychotic symptoms in BD are associated with a more severe, predominantly manic illness course. Mean age at onset was $27.76( \pm 8.54)$ years for patients with mood-congruent psychotic features and 28.00 ( \pm 11.08 ) years for patients with mood-incongruent psychotic features.
\end{abstract}

Key words: bipolar disorder, mood congruence, mood incongruence, psychotic features.

\section{Introduction}

Presence of any psychotic symptoms and illness is commonly mistaken for schizophrenia. Such a belief is often associated with chronic psychotic symptoms and poor psychosocial outcome. Psychosis is a commonly prevalent phenotype in bipolar disorder (BD), with more than half of all the individuals diagnosed with $\mathrm{BD}$ experiencing psychotic mood episodes in their lifetime (Dunayevich and Keck 2000). In some studies it has been found that psychotic symptoms or psychosis reported in acute mood episodes of BD (mania, depression and mixed states) is nearly equivalent to psychotic symptoms observed in schizophrenia (SCZ) (Pini et al. 2004; Keck et al. 2003). Nearly half of bipolar patients have a lifetime history of psychotic symptoms (Keck et al. 2003; Ozyildirim et al. 2010; Dell'Osso et al. 2017; Altamura et al. 2019). Indeed, across all jurisdictions, individuals with a diagnosis of BD make up a sizeable proportion of hospital admissions following a psychotic episode (Kirkbride et al. 2017; Simon et al. 2017). Psychotic symptomatology in bipolar mood disorder was dichotomized into mood-congruent and mood-incongruent delusions for the first time in DSM IV (APA, 2000). However, what do the terms 'mood-congruent' and 'mood-incongruent' mean? How do we differentiate the relationship between the content of delusional thoughts and an individual's mood? What justifies such estimation? Although the differentiation between mood-congruent and mood-incongruent delu- 
sions is now a common practice, the concept of mood congruence is sometimes criticized by researchers as being ambiguous (Maj 2008).

Lifetime prevalence of psychotic features in $\mathrm{BD}$ is associated with unfavourable socio-demographics and severity of clinical features as well as with a more frequent initial misdiagnosis of the disorder (Dell'Osso et al. 2017; Altamura et al. 2019). The lifetime presence of psychotic features in $\mathrm{BD}$ was found to be associated with more severe clinical features, including early age of onset, more substance abuse and social dysfunction as compared to non-psychotic features (Coryell et al. 2001; Kessing 2004; Dell'Osso et al. 2017).

The debate on the overlap of psychotic symptomatology in schizophrenia and BD from the perspective that these disorders may pose a diagnostic continuum with shared aetiology is ongoing (van Os and Reininghaus 2016). Some argue that the psychosis continuum extends from $\mathrm{BD}$ to schizoaffective disorder and at the other end typical schizophrenia, and reflects increasing severity (van Os et al. 2000; Craddock et al. 2005; The International Schizophrenia Consortium 2009).

Mood-congruent psychotic (MCP) symptoms including delusions and hallucinations that are consistent with manic/depressive episodes by their varied content of inflated self-esteem, power, identity, or special relationship with a famous person (APA 1994). Mood-incongruent psychotic (MIP) symptoms include persecutory thoughts unrelated to manic themes, such as persecutory delusions not directly related to grandiose themes, thought insertion, and delusions of being controlled (APA 1994). Schneiderian first-rank symptoms (Hales et al. 1994) are also considered to be mood incongruent in bipolar disorders (APA 1994).

Clarification of whether BD with psychotic features indeed reflects a greater degree of severity is an important inquiry in terms of nosology and treatment. As the field of psychiatry moves toward dimensional symptoms and functional descriptions rather than categorical classification, it will be helpful to have a better understanding of what features characterizes 'bipolar-spectrum' or 'psychotic-spectrum' illnesses and whether they require different targets for intervention. Recognizing similarities and differences between $\mathrm{BD}$ with and without psychotic features is also important for diagnostic classification and prognostic value. This knowledge may guide and aid treatment providers in clinical decision-making; if the presence of psychotic features is associated with poorer functioning, it might be necessary to target psychotic symptoms separately or more aggressively than mood symptoms. To address such queries, this study focuses on investigating the phenomenology of psychotic features, and demographic and clinical characteristics among an Indian population of participants with BD.

\section{Material and methods}

\section{Study population}

Inpatients from a psychiatry ward, diagnosed as having a bipolar mood disorder (manic/depressive/mixed) with psychotic features, admitted during a period of 1 year after approval of the Ethics Committee and in the age group between 18 and 65 years were included. Exclusion criteria: 1. Mood disorder secondary to medical or neurological illness; 2. Associated untreated medical condition, which can potentially cause development of psychotic features; e.g. untreated thyroid abnormalities or Cushing's syndrome (Santos et al. 2017); 3. Substance-induced mood disorder; 4. Pregnant patients.

\section{Methodology}

After obtaining approval from the Ethics Committee, this study was conducted. After obtaining the informed consent, patients were required to fill in a semi-structured proforma consisting of socio-demographic and clinical (illness variables and phenomenology of symptoms) details.

\section{Clinical assessment}

The diagnosis was established based on a clinical interview using the Structured Clinical Instrument for DSM-IV-TR (SCID) (First et al. 1997). Manic symptoms were assessed using Young's Mania Rating Scale (YMRS), depressive symptoms by the Montgomery-Åsberg Depression Rating Scale (MADRS) (Montgomery and Åsberg et al. 1979) and psychotic symptoms with the Scale for Assessment of Positive Symptoms (SAPS) (Andreasen 1984).

All data were collected in a single sitting and the average time to complete all the study related assessments by a patient was 50-60 minutes, approximately, but no fixed time limit was set. The assessments were administered by one group of researchers.

\section{Instruments used (scales)}

Structured Clinical Instrument for DSM-IVTR (SCID, First et al. 1997): The Structured 
Clinical Interview for DSM-IV Axis I Disorders (SCID-I) is a diagnostic examination used to determine DSM-IV Axis I disorders (major mental disorders). The instrument was designed to be administered by a mental health professional, for example, a psychologist or psychiatrist. This must be someone who has relevant professional training and has had experience performing unstructured, open-ended question, diagnostic evaluations. However, for some research studies, non-clinician research assistants, who have extensive experience with the study population in question, and who have demonstrated competence, have been trained to use the SCID. The less clinical experience and specific education the potential interviewer has had, the more training is required.

The Young Mania Rating Scale (YMRS, Young et al. 1978) is one of the most frequently utilized rating scales to assess manic symptoms. The scale has 11 items and is based on the patient's subjective report of his or her clinical condition over the previous 48 hours. Additional information is based on clinical observations made during the clinical interview. The items are selected based on published descriptions of the core symptoms of mania. The YMRS follows the style with each item given a severity rating. Four items are graded on a 0 to 8 scale (irritability, speech, thought content, and disruptive/ aggressive behaviour), while the remaining seven items are graded on a 0 to 4 scale. These four items are given twice the weight of the others to compensate for poor cooperation from severely ill patients. There are well-described anchor points for each grade of severity. The authors encourage the use of whole or half-point ratings once experience with the scale is acquired. Typical YMRS baseline scores can vary a lot. They depend on the patients' clinical features such as mania (YMRS $=12$ ), depression (YMRS $=3$ ), or euthymia (YMRS $=2$ ). Sometimes a clinical study entry requirement of $\mathrm{YMRS}>20$ generates a mean YMRS baseline of about 30. Strengths of the YMRS include its brevity, widely accepted use, and ease of administration. The usefulness of the scale is limited in populations with diagnoses other than mania. The YMRS is a rating scale used to evaluate manic symptoms at baseline and over time in individuals with mania. The scale is generally done by a clinician or other trained rater with expertise with manic patients and takes 15-30 minutes to complete.

Montgomery-Åsberg Depression Rating Scale (MADRS): This instrument consists of nine questions where one can get from 0 to 6 points (so theoretically can have between 0 and 54 points in total). The grading is based on a clinical interview moving from broadly worded questions about symptoms to more detailed questions that allow a precise assessment of severity. The interviewer must determine whether the assessment is on one of the defined steps on the scale $(0,2,4,6)$ or between them $(1,3,5)$. The questionnaire includes questions on the following symptoms 1 . Apparent sadness, 2. Reported sadness, 3. Inner tension, 4. Reduced sleep, 5. Reduced appetite, 6. Concentration difficulties, 7. Lassitude, 8. Inability to feel, 9. Pessimistic thoughts, 10. Suicidal thoughts.

Usual cut-off points are: 0 to 6 - normal/ symptoms absent; 7 to 19 - mild depression; 20 to $34-$ moderate depression; $>34-$ severe depression.

Scale for the Assessment of Positive Symptoms (SAPS) has 30 items and provides coverage of hallucinations, delusions, and behavioural changes associated with psychosis and was developed for schizophrenia. Information is acquired from both the patient and an informant. Each SAPS item is scored on a 6-point Likert-type scale (0-5). The sum of the 4 global domains (hallucinations, delusions, bizarre behaviour, and formal thought disorder) produces a summary score of $0-20$, and the sum of the 30 individual items provides a composite score of 0-150.

\section{Statistical analysis}

Descriptive statistics were used to describe the data, frequencies and percentages for categorical variables and mean and SD for continuous variables. The independent samples $t$-test was used to assess continuous variables, while the $\chi^{2}$ test was used to assess categorical data. These analyses were carried out using SPSS v. 20.0. Significance was set at $p<0.05$ (two-tailed).

\section{Results}

This study included patients hospitalized for a manic, depressive or mixed episode of $\mathrm{BD}$, who fulfilled the study inclusion criteria. From all the inpatients during 1 year, 212 patients were diagnosed as suffering from BD as per Diagnostic and Statistical Manual IV-TR (DSM-IV-TR). Amongst those diagnosed, 24 did not give consent, and hence were excluded from the study, while the remaining 188 patients were included in the study (the response rate being 88.6\%). 92 patients out of our sample $(n=188)$ were having psychotic features (48.94\%) (moodcongruent/incongruent). 86 out of those 
$92(93.47 \%)$ were diagnosed as having moodcongruent psychotic features and the remaining patients were diagnosed as having moodincongruent psychotic features $(n=6)(6.53 \%)$. Amongst the patients who had mood-congruent psychotic features, 68 (79.07\%) were manic, $15(17.44 \%)$ were depressed and $3(3.49 \%)$ were having a mixed episode, as mentioned in Table 1.

The mean age for mood-congruent and mood-incongruent patients were respectively $35.22( \pm 12.12)$ years and $37.67( \pm 11.86)$ years. Amongst those with mood-congruent psychotic features, $51(59.30 \%)$ were male and $35(40.70 \%)$ were female. Amongst those with mood-incongruent psychotic features $5(83.33 \%)$ were male and $1(16.67 \%)$ was female. Mean education in years was $7.66(4.43)$ and 5.50 (4.59) respectively for mood-congruent and mood-incongruent psychotic features. $76.64 \%$ $(n=66)$ of Hindus, $20.93 \%(n=18)$ of Muslims, $1.16 \%(n=1)$ of Christians and $1.16 \%$ $(n=1)$ of Sikhs had mood-congruent psychotic features, while $83.33 \%(n=5)$ of Hindus and $16.67 \%(n=1)$ of Muslims had mood-incongruent psychotic features. Religion was found to be statistically insignificant in our study. 20 (23.26\%) patients were single, $60(69.77 \%)$ married and $6(6.98 \%)$ were divorced amongst those who displayed mood-congruent psychotic features while $1(16.67 \%)$ patient who had mood-incongruent psychotic features was single and $5(63.33 \%)$ were married. $32(38.37 \%)$ were housewives, $12(13.95 \%)$ were labourers, $6(6.98 \%)$ students, $12(13.95 \%)$ were involved in skilled, $18(20.95 \%)$ in unskilled work and $5(5.81 \%)$ were unemployed amongst the moodcongruent psychotic features sub-group, while $1(16.67 \%)$ patient was a housewife, $3(50.0 \%)$ labourers, and $2(33.33 \%)$ were involved in skilled work in the group of patients having mood-incongruent psychotic features (Table 2).

Mean age at onset was $27.76( \pm 8.54)$ years for patients with mood-congruent psychotic features and $28.00( \pm 11.08)$ years for patients with mood-incongruent psychotic features. $62(72.09 \%), 18(20.98 \%)$ and $6(6.98 \%)$ patients with mood-congruent psychotic features had the first episode as manic, depressive and mixed polarity respectively. $5(83.33 \%)$ and $1(16.67 \%)$ patients with mood-incongruent psychotics features had the first-episode polarity as, respectively, manic and depressive. Mean number of previous episodes for manic, depressive and mixed type were respectively $2.59( \pm 2.17), 0.90( \pm 1.89)$ and $0.16( \pm 0.48)$ for mood-congruent psychotic features while the mean number of the previous episodes of mania and depression for mood-incongruent sub-group were respectively $2.33( \pm 1.51)$ and 0.83 ( \pm 0.75$)$. Family history for major depression, bipolar disorder and schizophrenia were respectively $2(2.33 \%), 25(29.07 \%)$ and $1(1.16 \%)$ for mood-congruent psychotic features. Family history for depression in patients with mood-incongruent psychotic features was $1(6.67 \%)$. In patients with mood-congruent psychotic features, $29.07 \%(n=25)$ of patients had a positive family history for BD. Two (2.33\%) patients with mood-congruent psychotic features had a lifetime history of a suicide attempt. There was no lifetime history of suicide in patients with mood-incongruent psychotic features. Amongst those with mood-congruent psychotic features, $40(46.51 \%)$ had no psychoactive substance use, $25(29.07 \%)$ had nicotine use, $11(12.07 \%)$ alcohol, $2(2.33 \%)$ cannabis use and $8(9.30 \%)$ patients had use of both alcohol and cannabis. $1(16.67 \%)$ of the patients with mood-incongruent psychotic features had no psychoactive substance use, $3(50.0 \%)$ and $1(16.67 \%)$ patients with mood-incongruent psychotic features had respectively use of no psychoactive substance, nicotine, alcohol and alcohol with cannabis. $62(72.09 \%)$ and $5(83.33 \%)$ patients had a history of electroconvulsive therapy (ECT) administration in their lifetime for mood-congruent psychotic features and mood-incongruent psychotic features, respectively (Table 3).

Table 1. Prevalence of mood-congruent psychotic features and mood incongruent psychotic features in bipolar disorder $(n=92)$

\begin{tabular}{lcc} 
Variable & Cases $(\boldsymbol{n})$ & Prevalence (\%) \\
Total patients with bipolar disorder & 188 & 100.00 \\
\hline Patients with psychotic features & 92 & 48.94 \\
\hline Mood-congruent psychotic features & 86 & $45.74(93.47)^{\mathrm{a}}$ \\
\hline Mania & 68 & $36.17(73.91)^{\mathrm{a}}$ \\
\hline Depression & 15 & $7.98(16.30)^{\mathrm{a}}$ \\
\hline Mixed & 3 & $1.59(3.26)^{\mathrm{a}}$ \\
\hline Mood-incongruent psychotic features (all manic patients) & 6 & $3.19(6.52)^{\mathrm{a}}$ \\
\hline${ }^{\mathrm{a}}$ Prevalence of psychotic features out of total bipolar disorder & &
\end{tabular}


Table 2. Socio-demographic characteristics of patients with mood-congruent and mood-incongruent psychotic features in bipolar disorder $(n=92)$

\begin{tabular}{|c|c|c|c|c|}
\hline Variable & $\begin{array}{l}\text { Mood-congruent } \\
\text { psychotic features } \\
\qquad n=86 \\
\text { Mean (SD)/n (\%) }\end{array}$ & $\begin{array}{l}\text { Mood-incongruent } \\
\text { psychotic features } \\
\qquad n=6 \\
\text { Mean (SD)/n (\%) }\end{array}$ & $t$ or $\chi^{2 *}$-value & $p$-value \\
\hline Age (years) & $35.22(12.12)$ & 37.67 (11.86) & -0.48 & 0.633 \\
\hline Gender & & & 1.36 & 0.244 \\
\hline Male & $51(59.30 \%)$ & $5(83.33 \%)$ & & \\
\hline Female & 35 (40.70\%) & $1(16.67 \%)$ & & \\
\hline Education (years) & $7.66(4.43)$ & $5.50(4.59)$ & 1.16 & 0.251 \\
\hline Religion & & & 0.22 & 0.974 \\
\hline Hindu & $66(76.74 \%)$ & $5(83.33 \%)$ & & \\
\hline Muslim & $18(20.93 \%)$ & $1(16.67 \%)$ & & \\
\hline Christian & $1(1.16 \%)$ & $0(0 \%)$ & & \\
\hline Sikh & $1(1.16 \%)$ & $0(0 \%)$ & & \\
\hline Marital status & & & 0.67 & 0.715 \\
\hline Single & $20(23.26 \%)$ & $1(16.67 \%)$ & & \\
\hline Married & $60(69.77 \%)$ & $5(83.33 \%)$ & & \\
\hline Divorced & $6(6.98 \%)$ & $0(0 \%)$ & & \\
\hline Occupation & & & 8.59 & 0.126 \\
\hline Housewife & 33 (38.37\%) & $1(16.67 \%)$ & & \\
\hline Labourer & 12 (13.95\%) & $3(50.00 \%)$ & & \\
\hline Student & $6(6.98 \%)$ & $0(0 \%)$ & & \\
\hline Skilled & $12(13.95 \%)$ & $2(33.33 \%)$ & & \\
\hline Unskilled & $18(20.93 \%)$ & $0(0 \%)$ & & \\
\hline Unemployed & $5(5.81 \%)$ & $0(0 \%)$ & & \\
\hline
\end{tabular}

The types of delusions were found to be significantly associated with mood congruency/ in-congruency of the index mood episode. A statistically significant difference $(p=0.000)$ was found for grandiose delusion $(72.09 \%, n=63)$ and religious delusion $(8.11 \%, n=7)$ in patients with mood-congruent psychotic features. This finding is consistent with the manic symptomatology given in the DSM-IV-TR. A statistically significant difference $(p=0.000$ significance) was found for delusional jealousy, i.e. 100\% $(n=6)$ in manic patients with mood-incongruent psychotic features (Tables 4, 5).

Patients with bipolar depression with moodcongruent psychotic features were found to have a statistically significant difference $(p=0.000$ significant) in the study in having guilt, $6.67 \%(n=1)$, reference, $33.33 \%$ $(n=5)$, jealousy, $33.33 \%(n=5)$, and persecutory delusions, $26.67 \%(n=4)$, which also are consistent with the depressive symptomatology given in DSM-IV-TR. In our study, patients having mixed mood features with mood-congruent psychotic features were found to have a statistically significant difference ( $p=0.000$ significant) in the study in having grandiose, $66.67 \%(n=2)$, and persecutory, $33.33 \%(n=1)$, delusions.

YMRS total scores were $39.16( \pm 7.18)$ and 27.67 (3.93) in patients with mood-congruent psychotic features and mood-incongruent psychotic features, respectively, which means that patients with mood-congruent psychotic features were found to have more severe manic features ( $p=0.000$, significant) than mood-incongruent psychotic features. MADRS total score was 40.07 $( \pm 3.96)$ in patients with mood-congruent psychotic features. No statistically significant difference was found in SAPS score $[27.22( \pm 11.42)$ and $29.67( \pm 1.51)$ in patients with mood-congruent and mood-incongruent psychotic features respectively $(p<0.05)$ ] (Table 6).

\section{Discussion}

In our study, almost half the total BD patients had associated psychotic features. Of these, the majority had mood-congruent psychotic features 
Table 3. Characteristics of illness variables correlation in patients with mood-congruent and mood-incongruent psychotic features in bipolar disorder $(n=92)$

\begin{tabular}{|c|c|c|c|c|}
\hline Variable & $\begin{array}{l}\text { Mood-congruent } \\
\text { psychotic features } \\
\quad n=86 \\
\text { Mean (SD)/n (\%) }\end{array}$ & $\begin{array}{l}\text { Mood-incongruent } \\
\text { psychotic features } \\
\qquad n=6 \\
\text { Mean (SD)/n (\%) }\end{array}$ & $t$ or $\chi^{2 *}$-value & $\begin{array}{c}p \text {-value } \\
>0.05\end{array}$ \\
\hline Age at onset & $25.76(8.54)$ & $28.00(11.08)$ & -0.39 & 0.696 \\
\hline \multicolumn{3}{|l|}{$1^{\text {st }}$ episode polarity } & 0.57 & 0.754 \\
\hline Manic & $62(72.09 \%)$ & $5(83.33 \%)$ & & \\
\hline Depression & $18(20.93 \%)$ & $1(16.67 \%)$ & & \\
\hline Mixed & $6(6.98 \%)$ & $0(0 \%)$ & & \\
\hline \multicolumn{3}{|l|}{ Current episode } & 1.56 & 0.458 \\
\hline Manic & $68(79.07 \%)$ & $6(100.00 \%)$ & & \\
\hline Depression & $15(17.44 \%)$ & $0(0 \%)$ & & \\
\hline Mixed & $3(3.49 \%)$ & $0(0 \%)$ & & \\
\hline No previous manic episode & $2.59(2.17)$ & $2.33(1.51)$ & 0.29 & 0.774 \\
\hline No previous depressive episode & $0.90(1.89)$ & $0.83(0.75)$ & 0.08 & 0.937 \\
\hline No previous mixed episode & $0.16(0.48)$ & $0(0)$ & 0.87 & 0.387 \\
\hline \multicolumn{3}{|l|}{ Family history } & 3.91 & 0.271 \\
\hline $\mathrm{Nil}$ & $58(67.44 \%)$ & $5(88.33 \%)$ & & \\
\hline Depression & $2(2.33 \%)$ & $1(16.67 \%)$ & & \\
\hline Bipolar disorder & $25(29.07 \%)$ & $0(0 \%)$ & & \\
\hline Schizophrenia & $1(1.16 \%)$ & $0(0 \%)$ & & \\
\hline \multicolumn{3}{|l|}{ Suicide attempt, lifetime } & 0.14 & 0.706 \\
\hline Yes & $2(2.33 \%)$ & $0(0 \%)$ & & \\
\hline No & $84(97.67 \%)$ & $6(100.00 \%)$ & & \\
\hline \multicolumn{3}{|l|}{ Substance use } & 6.98 & 0.137 \\
\hline Nil & $40(46.51 \%)$ & $1(16.67 \%)$ & & \\
\hline Nicotine & $25(29.07 \%)$ & $1(16.67 \%)$ & & \\
\hline Alcohol & $11(12.79 \%)$ & $3(50.00 \%)$ & & \\
\hline Cannabis & $2(2.33 \%)$ & $0(0 \%)$ & & \\
\hline Alcohol + cannabis & $8(9.30 \%)$ & $1(16.67 \%)$ & & \\
\hline \multicolumn{3}{|l|}{ History ECT lifetime } & 0.36 & 0.550 \\
\hline Yes & $62(72.09 \%)$ & $5(83.33 \%)$ & & \\
\hline No & $24(27.91 \%)$ & $1(16.67 \%)$ & & \\
\hline
\end{tabular}

Values for categorical and continuous variable are expressed in percentages and mean \pm SD, respectively. $p>0.05$

and they were found primarily in patients with manic symptoms.

No statistically significant correlation was found between socio-demographic and illnessrelated variables and psychotic features.

The most common mood-congruent psychotic features were grandiose delusions followed by religious delusions while a common finding in mood-incongruent psychotic features was delusion of jealousy. These observations were consistent with symptomatology described in DSM-IV-TR.

The study found that the Young's Mania Rating Scale score was significantly higher for those with mood-congruent psychotic features as compared to mood-incongruent psychotic features while Scale for Assessment of Positive Symptoms scores showed no significant difference between the two.

\section{Prevalence of psychotic symptoms}

In our study, $45.74 \%$ of patients had moodcongruent psychotic features, which was comparable to the results obtained in previous studies by Tohen et al. (1992) and Keck et al. (2003) (44.4\% and $39.0 \%$ had moodincongruent psychotic features respectively). 
Table 4. Phenomenology of psychotic symptoms score in mood-congruent verses mood-incongruent psychotic patients

\begin{tabular}{|c|c|c|c|c|}
\hline Variable & $\begin{array}{l}\text { Mood-congruent } \\
\text { psychotic features } \\
\text { (both mania and } \\
\text { depression) } \\
n=86(\%)\end{array}$ & $\begin{array}{c}\text { Mood-incongruent } \\
\text { psychotic features } \\
n=6(\%)\end{array}$ & $\chi^{2}$-value & $p$-value \\
\hline \multicolumn{3}{|l|}{ SAPS item score } & \multirow[t]{7}{*}{34.85} & \multirow[t]{7}{*}{$0.000^{*}$} \\
\hline Grandiose delusions & $63(72.09 \%)$ & $0(0 \%)$ & & \\
\hline Religious delusions & 7 (8.14\%) & $0(0 \%)$ & & \\
\hline Guilt delusions & $1(1.16 \%)$ & $0(0 \%)$ & & \\
\hline Reference delusions & $5(5.81 \%)$ & $0(0 \%)$ & & \\
\hline Jealous delusions & $5(5.81 \%)$ & $6(100.00 \%)$ & & \\
\hline Persecutory delusions & $5(5.81 \%)$ & $0(0 \%)$ & & \\
\hline
\end{tabular}

Table 5. Types of delusions in mood-congruent psychotic features in bipolar disorder $(n=86)$

\begin{tabular}{|c|c|c|c|c|c|}
\hline Type of delusions & $\begin{array}{c}\text { Mania } \\
(n=68)\end{array}$ & $\begin{array}{l}\text { Depression } \\
\quad(n=15)\end{array}$ & $\begin{array}{l}\text { Mixed } \\
(n=3)\end{array}$ & $\chi^{2}$ value & $p$-value \\
\hline Grandiose delusions & $61(89.71 \%)$ & $0(0 \%)$ & $2(66.67 \%)$ & \multirow[t]{6}{*}{86.52} & \multirow[t]{6}{*}{$0.000^{*}$} \\
\hline Religious delusions & $7(10.29 \%)$ & $0(0 \%)$ & $0(0 \%)$ & & \\
\hline Guilt delusions & $0(0 \%)$ & $1(6.67 \%)$ & $0(0 \%)$ & & \\
\hline Reference delusions & $0(0 \%)$ & $5(33.33 \%)$ & $0(0 \%)$ & & \\
\hline Jealous delusions & $0(0 \%)$ & $5(33.33 \%)$ & $0(0 \%)$ & & \\
\hline Persecutory delusions & $0(0 \%)$ & $4(26.67 \%)$ & $1(33.33 \%)$ & & \\
\hline
\end{tabular}

${ }^{*} p<0.001$

Table 6. Manic, depressive and positive symptoms in patients with mood-congruent and mood-incongruent psychotic features in bipolar disorder $(n=92)$

\begin{tabular}{lcccc} 
& $\begin{array}{c}\text { Mood-congruent psychotic } \\
\text { features } \\
\text { Mean (SD) }\end{array}$ & $\begin{array}{c}\text { Mood-incongruent psychotic } \\
\text { features } \\
\text { Mean (SD) }\end{array}$ & t-value & $p$-value \\
YMRS total score & $39.16(7.18), n=68$ & $27.67(3.93), n=6$ & 3.86 & $0.000^{*}$ \\
\hline MADRS total score & $40.07(3.96), n=15$ & $n=0$ & - & 0.52 \\
\hline SAPS total score & $27.22(11.42), n=86$ & $29.67(1.51), n=6$ & 0.603 \\
\hline${ }^{*} p<0.01$ & & &
\end{tabular}

A study from Italy by Altamura et al. in 2019 found presence of lifetime psychotic symptoms in $46.7 \%$ of the sample population. In our study, $3.19 \%$ of patients had mood-incongruent psychotic features while van Bergen et al. (2019), Azorin et al. (2006) and Tohen et al. (1992) reported that $21.2 \%, 33.4 \%$ and $55.6 \%$ of patients had mood-incongruent psychotic features respectively. A lower rate of prevalence of mood-incongruent psychotic features was found in our study population as compared to other above-mentioned studies from different parts of the world, which may be due to differences in sample size, race, methodology, screening instruments, gender distribution, lack of longitudinal studies and genetic susceptibility.

\section{Demographic characteristics and life course}

Tohen et al. (1992) reported that 30 (55.6\%) female and $24(44.4 \%)$ male patients had either mood-congruent or mood-incongruent psychotic features but psychotic features were not dichotomized into either mood-congruent or incongruent in this study. Azorin et al. (2006) also reported that a higher proportion of female patients (67.2\%) had mood-congruent psychotic features as compared to males (51.1\%). Toni et al. (2001) reported females representing $49.3 \%$ $(n=34)$ of patients having mood-incongruent psychotic features and $46.5 \%(n=40)$ of patients having either mood-congruent or no psychotic features. Marneros et al. (2009) also 
reported females comprising $60.0 \%(n=37)$ of the sub-group having mood-incongruent psychotic features and $43 \%(n=52)$ of the sub-group with mood-congruent or no psychotic features. These studies have indicated the possibility of higher prevalence of mood-incongruent psychotic features in female gender. Our study found no significant correlation between gender and presence of mood-incongruent psychotic features (which may due to cultural difference). In this study, mean education in years was 7.66 (4.43) and 5.50 (4.59) respectively for moodcongruent and mood-incongruent psychotic features. Toni et al. (2001) reported that most patients of both groups attended eight or more years of school. No significant correlation with education level was found in our and other studies. Religion as a socio-demographic variable was not considered in previous studies but we factored it in due to the cultural diversity of our study population. We found it to be statistically insignificant.

Azorin et al. (2006) reported higher representation of single, divorced or widowed in the mood-congruent psychotic group while in our study, the majority were married. These differences might be due to sample biases and our social structure discouraging post-marital separation. Tohen et al. (1992) reported that $16(29.6 \%)$ were married and $38(70.4 \%)$ were unmarried in their study group. Toni et al. (2001) reported $46.4 \%$ being married and $13.8 \%$ unmarried patients in their mood-incongruent psychotic feature group. Marneros et al. (2009) did not study marital status in patients with the psychotic feature of either type.

Azorin et al. (2006) and Marneros et al. (2009) did not study the correlation of occupation with psychotic features in bipolar disorder. Toni $e t$ al. (2001) found that $18.8 \%$ were housewives, $18.6 \%$ were involved in blue-collar jobs (semiskilled/unskilled), $10.1 \%$ in white-collar jobs (skilled) and $15.9 \%$ were unemployed in the mood-incongruent psychotic features subgroup. In our study, the occupation was not found to be significantly associated with any of the study variables. Age at onset (of $1^{\text {st }}$ episode) was very similar to the mean reported by Azorin et al. (2006) respectively for mood-congruent and incongruent subtype, $27.4( \pm 10.4)$ and 25.9 $( \pm 9.1)$. In addition, Dell'Osso et al. (2017) found that mean age at onset was $27.7 \pm 10.5$ in bipolar patients with psychotic symptoms. A statistically significant difference in age of onset of the first episode between mood-congruent and mood-incongruent psychotic symptoms was not observed, corroborating previous reports (Kendler 1991; Toni et al. 2001; Keck et al. 2003).

Azorin et al. (2006) reported that 103 (57.5\%), $51(28.5 \%)$ and $25(14.0 \%)$ patients with mood-congruent psychotic features had the first-episode polarity as respectively manic, depressive and mixed episodes, while 224 (61.5\%), $94(25.8 \%)$ and $46(12.6 \%)$ patients with mood-incongruent psychotic features had the first-episode polarity respectively as manic, depressive and mixed. Toni et al. (2001) reported that $29(42.0 \%), 33(47.8 \%)$ and $7(10.1 \%)$ patients with mood-incongruent psychotic features had the first-episode polarity respectively as manic, depressive and mixed episode. $21(24.4 \%), 55(63.9 \%)$ and $10(11.8 \%)$ patients with no mood-incongruent psychotic features had the first-episode polarity respectively as mania, depressive and mixed episode. Dell'Osso et al. (2017) reported that $55.2 \%$ and $24.4 \%$ of patients with psychotic features had the firstepisode polarity respectively as elevated and depressive $(p<0.001)$. As in previous studies (Kendler 1991; Toni et al. 2001; Keck et al. 2003), no statistically significant differences between the two groups was found for the first episode polarity in the current study. Marneros et al. (2009) did not report the first episode polarity in both groups.

Azorin et al. (2006) reported that the mean number of previous episodes was $6.2( \pm 6.1)$ and $7.2( \pm 6.9)$ respectively for mood-congruent and mood-incongruent psychotic features; however, no further classifications were done in this study. Marneros et al. (2009) reported that the mean number of previous episodes was $8.3( \pm 6.18)$ and $6.13( \pm 5.14)$ respectively for mood-incongruent psychotic features and without mood-incongruent psychotic features. In our study, no significance was found for the number of previous episodes according to polarity, similar to the findings of previous studies (Kendler 1991; Toni et al. 2001; Keck et al. 2003). In our study, in patients with moodcongruent psychotic features, $29.07 \%(n=25)$ of patients had a positive family history for BD. Toni et al. (2001) reported that the percentage for positive family history for major depression was $29.0 \%(n=20)$ and bipolar disorders $26.1 \%$ $(n=18)$ in patients with mood-congruent psychotic features while $22.1 \%(n=19)$ and $18.6 \%$ $(n=16)$ had a positive family history for major depression and BD respectively in patients with mood-incongruent psychotic features.

No patients with mood-incongruent psychotic features and 2 patients with mood-congruent 
psychotic features were found to have lifetime history of suicide in our study. Azorin et al. (2006) reported that $1(2.2 \%)$ patient with mood-incongruent psychotic features and 0.9 $( \pm 2.9)$ patients with mood-congruent psychotic features had a positive history of a suicide attempt. Tohen et al. (1992) reported that $3(4.3 \%)$ patients with mood-incongruent psychotic features had attempted suicide in the current episode. Our study results are in accordance with the above-mentioned studies for lifetime incidence of a suicide attempt. In contrast, Dell'Osso et al. (2017) found 25.6\% of patients with psychotic symptoms had a lifetime history of attempted suicide. More than half the patients in both sub-groups had a history of psychoactive substance use. Substance use was not taken into consideration by Tohen et al. (1992), Azorin et al. (2006), and Marneros et al. (2009) in their patient groups. Only 24 (27.91\%) and $1(16.67 \%)$ patients with mood-congruent and mood-incongruent psychotic features had no history of electroconvulsive therapy in their lifetime, respectively. Tohen et al. (1992), Azorin et al. (2006) and Marneros et al. (2009) did not study this variable. This may be due to the fact that our study was conducted in the western region of India, where electroconvulsive therapy (ECT) is frequently used as treatment modality.

\section{Clinical characteristics}

Azorin et al. (2006) found a statistically significant difference for grandiose, religious, somatic and referential delusions. Toni et al. (2001) reported significant presence of persecutory and referential delusions in patients with mood-incongruent psychotic features. Tohen et al. (1992) reported that $64.8 \%(n=35)$ of patients had paranoid delusions but did not mention about congruency or incongruency as they used DSM-III-R, in which this specifier was not mentioned. Toni et al. (2001) reported higher scores on auditory hallucinations in contrast to our study as no patients reported auditory hallucinations in either group. In our study, no statistically significant findings were obtained for thought withdrawal, thought insertion, thought broadcasting or delusions of control. A similar lack of findings was reported in previous studies by Toni et al. (2001) and Azorin et al. (2006) as far as thought phenomena are concerned. In our study, patients with depression with moodcongruent psychotic features were found to have a statistically significant difference $(p=0.000$, significant) for frequency of delusions of guilt
$6.67 \%(n=1)$, reference $33.33 \%(n=5)$, jealousy $33.33 \%(n=5)$ and persecutory delusions $26.67 \%(n=4)$, which is consistent with the depressive symptomatology given in DSM-IV-TR. However, no depressive patients were included in the studies by Tohen et al. (1992), Azorin et al. (2006) and Toni et al. (2001). In the study by Azorin et al. (2006) also, very similar results were obtained in this area, i.e. a statistically significant difference was obtained between the two groups in their YMRS total score. In addition, in the sample of the BD group, 916 patients (92.5\%) had experienced delusions. Within this group, $61.7 \%$ had a history of delusions of grandiosity, $61.5 \%$ delusions of reference, and $38.5 \%$ persecutory delusions, and symptoms including somatic, erotomanic delusions, and delusions of jealousy and guilt occurred in $39.9 \%$ of the psychotic patients. A history of hallucinations occurred in $58.0 \%$ of patients, of whom $33.4 \%$ had a history of auditory hallucinations and $39.0 \%$ visual hallucinations, while $20.9 \%$ had both (van Bergen et al. 2019).

\section{Limitations}

This study is a cross-sectional study so causality of an observed associated variable cannot be ascertained. The study was done in a hospital setting in inpatients only so the prevalence rate cannot be generalized to a larger population. Future multi-centric studies are required for applicability and generalization of the results.

\section{Conclusions}

Overall, our findings suggest that moodcongruent psychotic symptoms in BD are associated with a more severe, predominantly manic illness course. In future research, the role of recent genetic insights may provide a lead in further unravelling the aetiology of psychosis across psychiatric disorders.

\section{Disclosure}

The authors declare no conflict of interest.

\footnotetext{
References

1. Altamura AC, Buoli M, Cesana BM, et al. Psychotic versus non-psychotic bipolar disorder: Socio-demographic and clinical profiles in an Italian nationwide study. Aust N Z J Psychiatry 2019; 53: 772-781.

2. American Psychiatric Association. Diagnostic and statistical manual of mental disorders, $4^{\text {th }}$ ed. American Psychiatric Press, Washington, DC 1994.
} 
3. American Psychiatric Association. Diagnostic and statistical manual of mental disorders, $4^{\text {th }}$ ed., text revision. American Psychiatric Association, Washington 2000.

4. Andreasen NC. Scale for the assessment of negative symptoms (SANS). University of lowa, lowa City 1984.

5. Azorin JM, Akiskal H, Hantouche E. The mood-instability hypothesis in the origin of mood-congruent versus mood-incongruent psychotic distinction in mania: validation in a French National Study of 1090 patients. J Affect Disord 2006; 96: 215-223.

6. Coryell W, Leon AC, Turvey C, et al. The significance of psychotic features in manic episodes: a report from the NIMH collaborative study. J Affect Disord 2001; 67: 79-88.

7. Craddock N, O'Donovan MC, Owen MJ. The genetics of schizophrenia and bipolar disorder: dissecting psychosis. J Med Genet 2005; 42: 193-204.

8. Dell'Osso B, Camuri G, Cremaschi L, et al. Lifetime presence of psychotic symptoms in bipolar disorder is asso ciated with less favorable socio-demographic and certain clinical features. Compr Psychiatry 2017; 76: 169-176.

9. Dunayevich E, Keck PE Jr. Prevalence and description of psychotic features in bipolar mania. Curr Psychiatry Rep 2000; 2: 286-290.

10. First MB, Spitzer RL, Gibbon M, Williams JBW. Structured Clinical Interview for DSM-IV Axis I Disorders-Patient Edition (SCID-I/P, version 2.0). American Psychiatric Press, Inc., Washington, DC 1997.

11. Hales RE, Yudofsky SC, Talbott JA. The American Psychiatric Press Textbook of Psychiatry, $2^{\text {nd }}$ ed. American Psychiatric Press, Washington, DC 1994.

12. International Schizophrenia Consortium, Purcell SM, Wray NR, Stone JL, et al. Common polygenic variation contributes to risk of schizophrenia and bipolar disorder. Nature 2009; 460: 748-752.

13. Keck PE Jr, McElroy SL, Havens JR, et al. Psychosis in bipolar disorder: phenomenology and impact on morbidity and course of illness. Compr Psychiatry 2003; 44: 263-269.

14. Kendler KS. Mood-incongruent psychotic affective illness. A historical and empirical review. Arch Gen Psychiatry 1991; 48: 362-369.

15. Kessing LV. Subtypes of manic episodes according to ICD-10prediction of time to remission and risk of relapse. J Affect Disord 2004; 81: 279-285.

16. Kirkbride JB, Hameed Y, Ankireddypalli G, et al. The epidemiology of first-episode psychosis in early intervention in psychosis services: findings from the social epidemiology of psychoses in East Anglia [SEPEA] Study. Am J Psychiatry 2017; 174: 143-153.

17. Maj M. Delusions in major depressive disorder: recommendations for the DSM-V. Psychopathology 2008; 41: $1-3$.

18. Marneros A, Röttig S, Röttig D, et al. Bipolar I disorder with mood-incongruent psychotic symptoms: a comparative longitudinal study. Eur Arch Psychiatry Clin Neurosci 2009; 259: 131-136.

19. Montgomery SA, Asberg M. A new depression scale designed to be sensitive to change. Br J Psychiatry 1979; 134: 382-389.

20. Ozyildirim I, Cakir S, Yazici O. Impact of psychotic features on morbidity and course of illness in patients with bipolar disorder. Eur Psychiatry 2010; 25: 47-51.

21. Pini S, de Queiroz V, Dell'Osso L, et al. Cross-sectional similarities and differences between schizophrenia, schizoaffective disorder and mania or mixed mania with mood-incongruent psychotic features. Eur Psychiatry 2004; 19: 8-14.
22. Santos A, Resmini E, Pascual JC, et al. Psychiatric symptoms in patients with Cushing's syndrome: prevalence, diagnosis and management. Drugs 2017; 77: 829-842.

23. Simon GE, Coleman KJ, Yarborough BJH, et al. First presentation with psychotic symptoms in a population-based sample. Psychiatr Serv 2017; 68: 456-461.

24. Tohen M, Tsuang MT, Goodwin DC. Prediction of outcome in mania by mood-congruent or mood-incongruent psychotic features. Am J Psychiatry 1992; 149: 1580-1584.

25. Toni C, Perugi G, Mata B, et al. Is mood-incongruent manic psychosis a distinct subtype? Eur Arch Psychiatry Clin Neurosci 2001; 251: 12-17.

26. van Bergen AH, Verkooijen S, Vreeker A, et al. The characteristics of psychotic features in bipolar disorder. Psychol Med 2019; 49: 2036-2048.

27. van Os J, Hanssen M, Bijl RV, Ravelli A. Strauss (1969) revisited: a psychosis continuum in the general population? Schizophr Res 2000; 45: 11-20.

28. van Os J, Reininghaus U. Psychosis as a transdiagnostic and extended phenotype in the general population. World Psychiatry 2016; 15: 118-124.

29. Young RC, Biggs JT, Ziegler VE, Meyer DA. A rating scale for mania: reliability, validity and sensitivity. Br J Psychiatry 1978; 133: 429-435. 